\title{
ENVIRONMENTAL CONCERN OF POLLUTION IN RUBBER INDUSTRY
}

\author{
$\underline{\text { Santosh C. Jagadale* }}^{1}$, K.Rajkumar ${ }^{2}$, R.P.Chavan ${ }^{3}$, D.N.Shinde ${ }^{4}$, C.L.Patil ${ }^{5}$ \\ ${ }^{1,2}$ Indian Rubber Manufacturers Research Association, Plot No.254/1B, Road No.16V, Wagle Industrial Estate, Thane \\ (W)-400604. \\ ${ }^{1,3}$ Dnyanasadhana college, Department of Chemistry, Sathewadi off. Highway, Thane (W)-400604. \\ ${ }^{4,5}$ B.N.N. College, Varala Devi Road, Bhiwandi, Dhamankar Naka, Thane, Maharashtra 421305. \\ *1Corresponding Author E-mail.: santoshcj@gmail.com
}

\begin{abstract}
It is a known fact that Rubber Industry contributes in environmental pollution in different stages. Therefore this paper describes the information about a group of ingredients that causes pollution in the rubber industry. In a rubber product making process, different types of rubber chemicals and additives are added, depending on the requirement of ease of processing, improvement in properties in final product and cost reduction. Generally, rubber compound is made from basic raw rubber, activators, accelerators, fillers, plasticizers, antidegradants, curatives etc. While some other chemicals, such as: resins, wax, metallic coagents, dispersants, prevulcanising inhibitors, binders etc. are also added in order to achieve some special characteristic in the final product. These chemicals and or their complex with other ingredients are considered to be the cause of pollution to environment. Rubber products after use, becomes scrap and dealing with such scrap is a challenge to the Industries.
\end{abstract}

Keywords: Ingredients, hazardous, Activators, Accelerators, Curing Agent, Plasticizers, Fillers, Vulcanization

\section{INTRODUCTION}

Basic Polymer and ingredients used for making rubber products, either individually or after combinations make some carcinogenic gases and fumes during mixing, vulcanization process and even during storage. Also,chemical dust comes in contact with the air, some gets contaminated in water and thus, directly or indirectly, affects living things. However, waste disposal management is the big issue in the rubber manufacturing industry. The international standardization forum is continuously reviewing the effect of the use of rubber chemicals in the industry. There is need for use of biodegradable materials in compounding, avoiding human beings direct contact with ingredients, developing techniques that will reduce contamination of particles, gases and solvents released during the different processes of rubber product manufacturing and hence avoiding them from polluting the environment.

Rubber products are manufactured in different stages. Basically, natural or synthetic rubber is used as the basic rubber for the manufacturing process.

The typical manufacturing processes in rubber industry are as follows:

1. Raw material storage, handling and weighing

2. Milling of raw rubber, mixing rubber and rubber chemicals

3. Intermediate processes, such as sheeting, extruding and calendaring

4. Component assembly, building and pre-shaping

5. Vulcanization or curing of rubber compound

6. Product finishing, inspection\& testing
7. Packing, storage and dispatch.

In each of the above mentioned operational stages, there is the possibility of environmental pollution through dust, vapors, gases and fumes. They came in contact with air, water, soil and ultimately the environment. Many rubber product manufacturing units discharge their wastewater on land, rivulet and runnel. Few examples, this pollution includes (but not limited to):oil mixed water, water from mixing mills, water with chemicals from testing labs, product wash water and water with different ingredients from latex plants. This pollutes drinking water resources, land for irrigation, air and ultimately the whole environment. However, no information is available regarding the long term effect on soil, ground water and also on crops. A detailed study needs to be carried out in this regard. There is a need to upgrade production processes so as to decrease the amount of pollution from rubber industry. In thelatexindustry in order to increase dry rubber content (DRC) of latex, it is essential to remove water and other impurities. Also, in washing the product water is needed. All though maximum care is taken, recycling of water is done, many times, this contaminated water is released into the open ground or runnel. This may contain ammonia solution, Tetramethyl Thiuram Disulfide (TMTD), Zinc Oxide and diamonium phosphate. Appropriate and low-cost methods need to be explored in dealing with waste water from latex industry as well as in molded, extruded and other fabricated products, tyre and tube industry, reclaim rubber industry. Sengupta ${ }^{(1)}$ report on some waste water generation sources and the major water pollutants is given in table-1. 
Table-1

\begin{tabular}{|c|c|c|}
\hline $\begin{array}{l}\text { Type of } \\
\text { Industry }\end{array}$ & Waste Water Sources & Contaminant \\
\hline $\begin{array}{l}\text { Tyre and } \\
\text { Tube } \\
\text { Industry }\end{array}$ & $\begin{array}{l}\text { Cooling water bleed and boiler blow down, floor wash down of } \\
\text { different units (batch wise), leakages and spills contaminating } \\
\text { cooling water, accidental overflow from anti tack water tank, } \\
\text { sanitary and other miscellaneous water }\end{array}$ & $\begin{array}{l}\text { Oil and grease, Rubber fines, Anti } \\
\text { tack agents etc. }\end{array}$ \\
\hline $\begin{array}{l}\text { Moulded, } \\
\text { Extruded and } \\
\text { Fabricated } \\
\text { Products }\end{array}$ & $\begin{array}{l}\text { Cooling water bleed andboiler blowdown (batch wise), rinse and } \\
\text { product wash water (Batch wise),steam condensate with organic } \\
\text { leach (Batch wise), sanitary and other miscellaneous water }\end{array}$ & $\begin{array}{l}\text { Oil and grease, Rubber fines, } \\
\text { Antitack agents, powder as } \\
\text { fillers, etc. }\end{array}$ \\
\hline $\begin{array}{l}\text { Latex Based } \\
\text { Products }\end{array}$ & $\begin{array}{l}\text { Cooling water bleed and boiler blow down, product wash water, } \\
\text { wash down from latex storage, compounding and transfer areas, } \\
\text { form wash and rinse waters, accidental overflow water, sanitary and } \\
\text { other miscellaneous water, coagulation/coagulating agent tank } \\
\text { wash/over flow }\end{array}$ & $\begin{array}{l}\text { Latex spills, } \\
\text { surfactants, coagulants etc. Ball } \\
\text { milling and } \\
\text { washing containing } \\
\text { flow chemicals including } Z n \text {, } a \text { cid } \\
\text { (acetic / formic) etc. }\end{array}$ \\
\hline $\begin{array}{l}\text { Reclaimed } \\
\text { Rubber }\end{array}$ & $\begin{array}{l}\text { Cooling water bleed and boiler blow down, steam condensate from } \\
\text { autoclave, area wash down of all processing areas, sanitary and } \\
\text { other, miscellaneous water }\end{array}$ & $\begin{array}{l}\text { Oil and greases, soluble and } \\
\text { insoluble inorganics, rubber } \\
\text { particles }\end{array}$ \\
\hline
\end{tabular}

During the manufacturing and storage of rubber products, various gases, vapors, fumes and aerosols are emitted due to the leaching out of chemicals and also during vulcanization that occurs at high temperatures. These emissions consist of volatile components from the original compounding ingredients such as: plasticizers, antioxidants and residual monomers or polymer oligomers, as well as primary and secondary reaction products from the crosslinking systems. The formulae and vulcanization conditions of individual substances as well as their origin have been identified in numerous studies. ${ }^{(2-6)}$ These substances are amines, amides, aliphatic/aromatic hydrocarbons, highly volatile sulfur compounds, aldehydes and ketones, phenols and esters. ${ }^{(2-}$ ${ }^{6)}$ Fumes of solvents may also be present, depending on the manufacturing process, as these solvents are used for assembly and cleaning. Monitoring of the air quality at the workplace requires the implementation of a measurement method that is able to cope with the extremely complex situation in the rubber industry.

From material inward stage andstorage process, pollution starts. Generally it is due to the shortage of storage area, humid climate, storage temperature, improper ventilation, storage in contact with other chemicals, inadequate knowledge of product and its maintenance, loading and unloading of materialand the use of hooks and thus damaging the bags etc. are some reasons for contamination as well as spillage of these ingredients. Sometimes they are very casually handled by operatorse.g. without packing, they are openly taken towards the weighing machine and mixing machine. Some of them get in contact with air and may spread unpleasant odour and dust. During the mixing process, fillers are dumped on polymer in the mixing mill. During that process, a lot of chemical dust gets spread in to the air and the working area is affected, due to these dust particles. During the vulcanization process, fumes from heated or previously heated rubber createunpleasant odour which is a complex mixture of components and the associated hazard unknown. Epidemiological studies suggest that exposure to rubber fume may be a significant factor in the increased incidence of certain type of cancers and the cause of some other diseases. Airborne contamination from rubber fumes is either visible or nonvisible. The invisible pollutants are gases and vapors of low molecular weight organic compounds (carbon disulfide and amines) or inorganic (hydrogen sulfide) compounds. The visible pollutants arise from aerosols. These aerosols evolved during the mixing, milling, blending of elastomers or combination of them with chemicals involved in the process. The aerosol fraction of rubber fumes is complex and with unknown composition. ${ }^{(7)}$ The concentration of airborne aerosols is very considerable at the workplace in the rubber industry, and it should be monitored by approved trapping and detection methods. The major component of fumes is due to accelerators and their reactions with other ingredients of rubber compounds. For example, the major volatile component of tetramethyl thiuram disulfide (TMTD) and zinc dimethyl dithiocarbonate (ZDMC) accelerated cure, will include carbon di sulfide, dimethyl amine and sometimes hydrogen sulfide. ${ }^{(7)}$ In case of the latex industry ammonia solution added tolatex causes a strong smell. This can have adverse effect on workers health, especially the respiratory system.

Compounding Ingredients and their effect:Generally, rubber compound is made from basic polymer, activators, accelerators, fillers, plasticizers, antidegradants, curatives etc. The followings are some few examples of the precursors for pollution:

1. Polymers: Raw or base rubberis the major part of rubber product as far as the weight of complete rubber product is concerned. Natural rubber and synthetic rubbers are used in the rubber industry. Within each type, based on the chemical structure, method of production and functional group present in the structure, there are many grades. Generally, each rubber has its own characteristic smell. We can experience the same in the storage area, during the 
rubber mastication process and vulcanization process. It releases complex fumes and smell, which may either be individual or reactant products. Rubbers are highly flammable. After coming into contact with heat and flame, itignites spontaneously and generates considerable quantities of smoke while burning. Basic raw materials for synthetic polymer making are petro based products. It should be stored away from energy-generating sources such as boiler and oil storage room.

2. Fillers: In the rubber industry different types of fillers are used in order to improve the properties of rubber compound as well as for cost reduction. Few examples of such fillers are: carbon black, white fillers such as: silica, whiting, barytes, hard clay, soft clay etc. These contribute (in weight) the main part of rubber compounds.

2.1 Carbon Black: Approximately $65 \%$ of the carbon black is used in tyre production. In 1995 and more recently, in February 2006, the International Agency for Research on Cancer (IARC) ${ }^{(8)}$ conducted a comprehensive review of carbon black and concluded that there is limited evidence for carcinogenicity from carbon black, based on studies in humans. They concluded and classified carbon black as IARC classification 2B-possibly carcinogenic to humans and definitely carcinogenic to animals. Non-cancer respiratory effects in workers who work with carbon black have been reported include; cough, sputum production, bronchitis, chest radiographic opacities (e.g. Pneumoconiosis) and decrements in lung function. ${ }^{(8)}$ Shortterm exposure to high concentrations of carbon black dust may produce discomfort to the upper respiratory tract through mechanical irritation. ${ }^{(8)}$ As carbon is the precursor for $\mathrm{CO}_{2}$ emission and thus the warming of environment, there is the need topartially or completely replacecarbon black with ecofriendly and biodegradable material or its use should be kept as minimum as possible.

2.2 Silica: In case of crystalline silica dust, dust particle can cause fibrosis (scar tissue formation in the lungs). Silicosis is the respiratory disease of the lungs that caused due to the inhalation of airborne crystalline silica dust. Individuals with silicosis are at increased risk of developing pulmonary tuberculosis, if exposed to person with tuberculosis. ${ }^{(9)}$

2.3 Titanium dioxide $\left(\mathbf{T i O}_{2}\right)$ : There is inadequate evidence of carcinogenicity of titanium dioxide in humans, but there is sufficient evidence through experimental work on animals, for the carcinogenicity of titanium dioxide. Titanium dioxide is possibly carcinogenic to humans (Group 2B). ${ }^{(10)}$

2.4 Talc: In the case of talc, it is generally used as filler as well as dusting on rubber sheet in order to avoid sticking through adhesion of rubber sheet during storage. During dusting process, dust particles come in contact with the environment at working area.
3. Plasticizers: Plasticizers represent a special group of ingredients. They are used in the rubber industry as processing additives. They help in improving theprocessing of rubber as well as modify the physical and chemical properties of the rubber compound. The emission of carbon dioxide due to the consumption of fossil fuels is considerable in the rubber industry.In oils, based on aromatic content the important types are: aromatic oil, naphthenic oil and paraffinicoil. Also, there is one important group i.e. phthalates that are mostly used in poly vinyl chloride (PVC) and nitrile rubber. These are polar materials. They are released into the environment, either by spillage, in gaseous form, as odors, form complex structure with other ingredients and evaporate during the vulcanization stage at high temperature. The followingsare some of the examples.

3.1 Aromatic Process oils: They contain polycyclic aromatic hydrocarbons (PAHs) or polycyclic aromatic (PCA) which are carcinogen and can cause mutation. Regulations (European Directive 2005/69/EC) imposed ban of process oils containing $\geq 10 \mathrm{mg} / \mathrm{kg}$ ( $\mathrm{ppm}$ ) of PAH since $2010^{(11)}$ Aromatic process oils are labeled as carcinogenic under OSHA regulation ${ }^{(11)}$.

3.2 Phthalates: Within the phthalates there are different types. Some of the commonly used are dioctyl phthalate (DOP), di-butyl phthalate (DBP) etc. It has been welldocumented that endocrine disruptors, such as phthalates can be additive, therefore even very small amounts can interact with other chemicals to have cumulative, adverse "cocktail" effects. ${ }^{(12)}$ Phthalates in pure form are usually clear liquids, some with faint sweet odors and some with faint yellow color.With respect to health effects, phthalates are often classified as endocrine disruptors or hormonallyactive agents (HAAs) because of their ability to interfere with the endocrine system in the body. ${ }^{(13)}$ In many countries there is ban on phthalate plasticizers.

4. Activators: In the rubber industry zincoxide and stearic acid are used as activators. Generally,zinc oxide is used as a $5 \mathrm{phr}$ (parts hundred rubbers). Recently the tendency has been to use between $2-4 \mathrm{phr}$ and 3 is adequate in most purposes. The reduction is due to its high cost and high density. There is a more recent reason for the reduction of the zinc oxide quantity in rubber compound formulations. ${ }^{(14)}$ The US Environmental protection energy (EPA) has classified zinc oxide as toxic chemical. The earliest symptoms of this metal oxides fume is metallic taste in mouth, accompanied by dryness and irritation of the throat $^{(15)}$ in addition toflu-like symptoms, chills, fever, profuse sweating, headache and weakness. ${ }^{(16)}$ These symptoms usually occur within several hours after exposure to zinc oxide fumes and can persist for between 24- 48 hours.

5. Accelerators: These types of ingredients are used to accelerate the rate of vulcanization during the curing of rubber products. There are many types of accelerators, such as: amines, dithiocarbamates, guanidines, sulphenamides, thizoles, thioureas andthiurams etc. It is known that rubber 
fume can contain $\mathrm{N}$-nitrosamines. ${ }^{(17)}$ Many $\mathrm{N}$-nitrosamines are carcinogenic. They are formed incidentally, when certain precursor compounds coexist under favorable reaction conditions. Most commonly, they are formed in the rubber industry by the reaction of an amine with a nitrosating agent. ${ }^{(17)}$ A number of accelerators are based on secondary amines. Few examples: thiurams, dithiocarbamate, sulfanamides-based accelerators, are likely to generate nitrosamines during curing. Nitrosating agents can include atmospheric oxides of nitrogen (NOx), ${ }^{(17)}$ which are common pollutants from internal combustion engines, particularly diesel engines.

The volatile $\mathrm{N}$-nitrosamines are of most concern and they are the focus of the regulation. Measuring of Nnitrosamines emitted from elastomeric compounds is still an important issue that rubber industry has to deal with. The chemical pathways of nitrosamine formation and degradation in the atmosphere (particularly in the aqueous phase) remain uncertain. ${ }^{(18)}$ Exposureto nitrosamine has been shown to form tumors in laboratory animals and have been linked in epidemiological studies to human cancers, including pancreatic cancer (Risch,2003), childhood brain tumors (Huncharek and Kupelnick, 2004). Nitrosamines are classified by a number of international organizations and regulatory authorities in accordance to their carcinogenicity. Under the International Agency for Research on Cancer (IARC), which is part of the World Health Organization (WHO), N-nitrosodimethylamine (NDMA) and Nnitrosodiethylamine(NDEA) are classified as Group 2A substances (probably carcinogenic to humans). ${ }^{(18)}$ Earlierstudies ${ }^{(19)}$ have shown that Nnitrosamines are evolved from heated elastomers. More recent studies by Ireland et a1 (20) showed that $\mathrm{N}$ nitrosamines can be extracted in water from elastomers

6. Curing Agent: Generally, rubber curing is done by sulfur and peroxide. There are also other chemicals used such as: metal oxides, resin curing agent, sulphur donors as a curing agent. They generate fumes and smell during storage as well as vulcanization process.

During sulphur vulcanization with guanidine type accelerators (e.g. Diphenyl Guanidine-DPG, N,N' Di-OTolyguaniidine- DOTG) and antioxidants based on phenylene diamine, cancerogenic primary aromatic amines (PAA) and isothiocyanates (ITC) are formed inevitable. Respiratory morbidity has been associated with exposure in the rubber industry. (21-24) Chronic and acute bronchitis, decreased lung function, and airway symptoms have been observed. Weeks et al ${ }^{(23,25)}$ and Zuskin et al ${ }^{(24)}$ also surveyed other symptoms (e.g, headache and nausea) among workers doing vulcanization. However, environmental conditions have improved during the last few decades and little is known about health effects in the contemporary rubber industry.

During peroxide curing, it generates fumes and characteristic smell. In case of dust inhalation, continuous exposure may cause light irritation to the eyes and skin, irritating to nasal mucous membranes and upper respiratory tract. Generally peroxides are heat sensitive. These are to be protected from heat, as they easily catch fire and burn rapidly. In peroxide cured rubber products, sometimes, there is need for post vulcanization. During this process, a lot of fumes come in contact with air.

7. Antidegradants: This group of ingredients is used to protect the rubber article from degradation due to oxidation,ozone. These chemicals improvethe dynamic properties of rubber products. According to their types, they are phenolic, phosphates, thioesters, amines and other multifunctional types. Generally, they are volatile under severe temperature conditions, migrate towards surface of products and may give rise to staining and blooming. Antiozonant e.g. N-phenyl-N'-(1,3-dimethylbutyl)-pphenylenediamine (6PPD) partly decomposes and undergoes further reactions after migration in aqueous food simulants formingPrimary aromatic amines (PAA), which is a critical hygiene concern. ${ }^{(26)}$

These are the only few sources of pollution spreading. Besides this, there are many other sources such as: from scraps, cuttings, flash of rubber product, dust from rubber products grinding, different types of solvents that are used for cleaning and adhesive preparation, spillage from bags and oil drums, different types of dusting powders, surface finishing agents, waste water and chemicals from testing labs, oil leakages from machineries, cuttings, rejected and scrapped products e.g. tyre.

Suggestions and Basic Precautions: There is lot of scope for improvement. But some basic attention can minimize the issue at following levels:

1. Processing \& Storage: At the work area, during operation, masks, goggles, gloves and other safety wares should be used. The work area to be kept neat and clean. To prevent spreading of spilled chemicals, it is to be cleaned immediately. For collecting the material spread during storage and manufacturing process, dry vacuuming is the recommended method. Arrangement should be made for collecting fumes and dust. Fire extinguishers should be kept at working area at all times. Waste water treatment related care should be taken. The recycling of waste water must be done.

2. Selection of Material and Process: Rubber compound ingredients that are degradable, environment friendly, creates minimum pollution are to be selected. While designing compound formulation, the pollution and health hazard nature of the individual ingredient, should be taken into account.Material safety data sheet should be referred to, for precaution. Product making process should be properly designed where human contact with process-generating pollutants, will be minimum e.g. the use of machines having closed chambers from which contaminated air, fumes can be collected by suitable collecting arrangement should be employed.

3. Scrap: By using rubber as an auxiliary fuel in cement plants and heating plants, the fuel value of the waste can be utilized. However, large quantities of waste rubber still end- 
up in landfill. Recycling methods that are applied, to some extent, include: the reuse of scrap rubber in the form of finely ground powder in various rubber materials, and the mixing of rubber waste into asphalt. Chemical recovery methods are also used to a limited extent. Examples of these methods include pyrolysis, devulcanisation and the production of reclaimed rubber. The problem, however, is that vulcanization is an irreversible process.

\section{CONCLUSION}

In rubber industry for spreading pollution, different chemicals contribute. Also at different stages it occurs. The described data gives few examples of the chemicals from particular group ex. polymer, fillers, plasticizers, activators, accelerator, curing agent and antidegradants. During different stages of manufacturing, there is possibility of spreading pollution and same can be avoided and minimized by proper precautions. To avoid and minimize the pollution, there is need of proper storage, processing techniques, proper knowledge of chemicals, manpower training, proper selection of material, and developing the new techniques and methods for scrap disposal and reuse of scrap.

\section{REFERENCES}

[1] B.Sengupta, Central Pollution Control Board, Delhi, Development of Standards for Rubber Products Manufacturing Industry. 2007, 39-40

[2] R. H. Schuster, H.Linde and G.Wünsch, Kautsch. Gummi Kunstst. 44(1991) 222

[3] B. G. Willoughby and G. Lawson, Environ-Health Persp. 17(1976) 45

[4] V. Cocheo, M. L. Bellomo and G. G. Bombi, Am. Ind. Hyg. Ass. J. 44(1983) 521

[5] B. G. Willoughby, Rub. Chem. Technol. 54(1981) 311

[6] B. G. Willoughby, Europ. Rubber J. 166 (3)(1984) 49

[7] Health and safety in the rubber industry by N.Chaiear volume 12, number 6, 2001 page 22.

[8] IARC Monographs on the Evaluation of Carcinogenic Risks to Humans, Lyon, 7-14 February 2006, 2010 VOLUME 93 page 189.

[9] Health and safety in the rubber industry by N.Chaiear volume 12, number 6, 2001 page 21.

[10] IARC Monographs on the Evaluation of Carcinogenic Risks to Humans, Lyon, 7-14 February 2006, 2010 VOLUME 93 page 275.

[11] http://www.rubbercenter.org/images/file_pdf/introducti on_to_process_oils.pdf , KrishdaSuchiva, Research and Development Centre for Thai Rubber Industry, Mahidol University, Introduction to process oils, page 16.

[12] Waring R.H., Harris R.M. (2011). "Endocrine disrupters - a threat to women's health?"Maturitas68: 111-115. Doi: 10.1016/j.maturitas. 2010.10.008

[13] Wigle, D.T. 2003. "Hormonally Active Agents," in: Wigle, D.T., "Child Health and the Environment." Oxford, Oxford University Press, Inc.

[14] Rubber compounding: Principals: Materials, and Techniques, by Barlow second edition, chapter 9 page116.
[15] TOXICOLOGICAL REVIEW OF ZINC AND COMPOUNDS, EPA/635/R-05/002, July 2005, page no.60.

[16] Drinker et al., 1927a, b; Sturgis et al., 1927; Rohrs, 1957; Malo et al., 1990.

[17] http://www.hse.gov.uk/research/rrpdf/rr819.pdf , A small survey of exposure to rubber process dust, rubber fume and N-nitrosamines, Prepared by the Health and Safety Laboratory for the Health and Safety Executive 2010

[18]Dr. Noelle E. Selin, Environmental Guidelines and Regulations for Nitrosamines: A Policy Summary.

[19] Yeager FW, van Gulick NN, LasoskiBA.Dialkylnitrosamines in elastomers. Amind hygassoc j 41 (1980) 148-150.

[20] Ireland CB, Hytrek FP, Lasoski BA. Aqueous extraction of $\mathrm{N}$-nitrosamines from elastomers. Amind hygassoc j 41

[21] Fine LJ, Peters JM. Respiratory morbidity in rubber workers, I: prevalence of respiratory symptoms and disease in curingworkers. Arch Environ Health. 1976; 31(1):5-9.

[22] Fine LJ, Peters JM. Respiratory morbidity in rubber workers, I: pulmonary function in curing workers. Arch EnvironHealth. 1976; 31(1):10-4.

[23] Weeks JL, Peters JM, Monson RR. Screening for occupational health hazards in the rubber industry, part I. Am J Ind Med.1981;2(2):125-41.

[24]Zuskin E, Mustajbegovic J, Schachter EN, Doko-Jelinic J, Budak A. Longitudinal study of respiratory findings in rubberworkers. Am J Ind Med.1996; 30(2):171-9.

[25] Weeks JL, Peters JM, Monson RR. Screening for occupational health hazards in the rubber industry, part II: health hazards inthe curing department. Am J Ind Med. 1981; 2(2):143-51.

[26] Hans-Jurgen Kretzschmar Hazards in the European Rubber Industry: An Assessment of Exposure Risks; September 1999, paper 6 page 1. 